This is a post-peer-review, pre-copyedit version of an article published in O. Gervasi et al.

(Eds.) Computational Science and Its Applications - ICCSA 2020. Lecture Notes in

Computer Science. The final authenticated version is available online at:

https://doi.org/10.1007/978-3-030-58808-3_17

\title{
PLS Visualization Using Biplots: An Application to Team Effectiveness
}

\author{
Alberto Silva ${ }^{1,2}$ [0000-0002-3496-6802] , Isabel Dórdio Dimas 3,4 [0000-0003-4481-2644], Paulo Renato Lourenço ${ }^{3,5}$ [0000- \\ 0003-1405-3835], Teresa Rebelo ${ }^{3,5}$ [0000-0003-3380-0840], Adelaide Freitas ${ }^{1,2}$ [0000-0002-4685-1615] \\ ${ }^{1}$ Departament of Mathematics, University of Aveiro, 3810-193 Aveiro, Portugal \\ ${ }^{2}$ CIDMA, Center for Research \& Development in Mathematics and Applications, University of Aveiro, 3810-193 \\ Aveiro, Portugal \\ ${ }^{3}$ CeBER, Centre for Business and Economics Research, University of Coimbra, 3004-512 Coimbra, Portugal \\ ${ }^{4}$ FEUC, University of Coimbra, 3004-512 Coimbra, Portugal \\ ${ }^{5}$ FPCEUC, University of Coimbra, 3000-115 Coimbra, Portugal \\ albertos@ua.pt, idimas@fe.uc.pt, prenato@fpce.uc.pt, terebelo@fpce.uc.pt, \\ adelaide@ua.pt
}

\begin{abstract}
.
Based on a factorization provided by the Partial Least Square (PLS) methodo-logy, the construction of a biplot for both exploratory and predictive purposes was shown to visually identify patterns among response and explanatory variables in the same graph. An application on a team effectiveness research, collected from 82 teams from 57 Portuguese companies and their respective leaders, containing two effectiveness criteria (team performance and the quality of the group experience as response variables), was considered and interpretation of the biplot was analyzed in detail. Team effectiveness was considered as the result of the role played by thirteen variables: team trust (two dimensions), team psychological capital (four dimensions), collective behavior, transformational leadership, intragroup conflict (two dimensions), team psychological safety, and team cohesion (two dimensions). Results revealed that the biplot approach proposed was able to capture the most critical variables for the model and correctly assigned the signals and the strength of the regression coefficients. Regarding the response variable team performance, the most significant variables to the model were team efficacy, team optimism, and team psychological safety. Concerning the response variable quality of the group experience, intragroup conflict, team-trust, and team cohesion emerged as the most relevant predictors. Overall, the results found are convergent with the literature on team effectiveness.
\end{abstract}

Keywords: Partial Least Square, Biplot, Organizational Teams, Team Effectiveness

\section{Introduction}

Frequently, multivariate data analysis seeks to perceive the existing underlying structure and to understand the relationships established within data. Visual information via graphic displays can be a useful tool to explore the dataset since it summarizes the data more directly and improves its understanding (Koch, 2014). Likewise, a graph of the results of a specific statistical method, e.g., the Principal Component Analysis (PCA) biplot, enhances data familiarity. The biplot method permits visual evaluation of the structure of large data matrices through the approximation of a high-rank matrix by one of rank two. The PCA biplot represents observations with points and variables with arrows. Small distances between units can indicate the existence of clusters, while the size of an arrow depicts the standard deviation of the associated variable. Further, the angle between two vectors approximates the linear correlation of the related variables (Gabriel, 1971). 
When it comes to multivariate regression problems, sometimes one must fix some problems before applying any methodology to estimate parameters and thinking about the graphical representation of its results. This is the case of an ill-posed problem, in which the predictors are many and quasi-collinear, leading to an unstable Ordinary Least Squares (OLS) solution, i.e., the OLS estimates have high variance (Belsley, Kuh \& Welsch, 2004). Under this condition, the Partial Least Squares (PLS) regression gives better results, since it eliminates the quasi-collinearity issue. The PLS method extracts factors that maximize the covariance between the predictors and response variables, and then regresses the response on these latent factors. Based on the outputs of the PLS (scores, loadings, and weights vectors), the variances and correlations of the variables can be revealed by employing an exploratory PLS biplot. On the other hand, the PLS biplot can be adapted to provide a visual approximation of the PLS coefficient estimates, hence the reason for naming it predictive PLS biplot.

The primary purpose of this article is to provide a straightforward interpretation for the PLS biplot applicable to both exploratory and predictive purposes, illustrating its application in team effectiveness research data. Interest in understanding complex relationships between variables of team effectiveness datasets has been growing in recent years (Mathieu, Gallagher, Domingo, \& Klock, 2019; Ringle, Sarstedt, Mitchell, \& Gudergan) and the PLS biplot method can play a crucial role in the analysis of this kind of data.

In order to achieve the main aim of the present work, the paper is structured in the following sections: section 2 gives a brief overview of how PLS works, describing mathematical details; section 3 presents an application of these methods on a subset of variables of real work teams, exploring the relationships between a set of team effectiveness predictors (team trust, team psychological capital, collective behavior, transformational leadership, intragroup conflict, team psychological safety and team cohesion) and two team effectiveness criteria (team performance and quality of group experience). All the statistical analysis was executed using $\mathrm{R}$ software; finally, section 4 includes the discussion of the results found, as well as conclusions and future perspectives.

\section{Methods}

\subsection{Partial Least Squares}

Assume a multivariate regression model $\mathbf{Y}=\mathbf{X B}+\mathbf{E}$, in which $\mathbf{Y}$ is an $(n \times q)$ response matrix and $\mathbf{X}$ is a $(\mathrm{n} \times \mathrm{m})$ predictor matrix, and both are column centered, with $\mathrm{m}$ and $\mathrm{q}$ being respectively the number of predictors and response variables, and $\mathrm{n}$ the number of observations. Also, $\mathbf{B}$ is a $(\mathrm{m} \times \mathrm{q})$ coefficients matrix, and $\mathbf{E}$ is a $(n \times q)$ error matrix, such that $m>n$ or the $m$ explanatory variables are highly correlated. In this case, one might use the PLS to estimate the regression coefficients. The PLS model consists of three other models, two external and one internal, as a result of the application of a suitable algorithm, usually the Nonlinear Iterative Partial Least Squares (NIPALS). The method seeks to estimate some underlying factors that decompose $\mathbf{X}$ and $\mathbf{Y}$ simultaneously, maximizing the covariance between them, establishing the socalled outer relations for $\mathbf{X}$ and $\mathbf{Y}$ individually (Geladi \& Kowalsky, 1986). Considering the extraction of all possible factors, the PLS decomposition results in

$$
\mathbf{X}=\mathbf{T P}^{\prime} \text { and } \mathbf{Y}=\mathbf{U Q}^{\prime},
$$

where $\mathbf{T}$ contains the scores of the predictors' matrix, $\mathbf{P}$ holds the loadings of $\mathbf{X}$. In turn, $\mathbf{U}$ and $\mathbf{Q}$ are the matrices of scores and loadings relative to the response matrix $\mathbf{Y}$. Additionally, an inner relation links the $\mathbf{X}$-scores and $\mathbf{Y}$-scores matrices as follows:

$$
\widehat{\mathbf{u}}_{\mathbf{i}}=\mathrm{a}_{\mathbf{i}} \mathbf{t}_{\mathbf{i}},
$$

where

$$
a_{i}=\frac{\mathbf{u}_{\mathrm{i}}^{\prime} \mathbf{t}_{\mathrm{i}}}{\mathbf{t}_{\mathrm{i}}^{\prime} \mathbf{t}_{\mathrm{i}}}
$$

are the regression coefficients for a given factor. In order to ensure maximum covariance between $\mathbf{Y}$ and $\mathbf{X}$ when extracting PLS components, it is necessary to find two sets of weights $\mathbf{w}$ and $\mathbf{q}$, which allow the vectors $\mathbf{t}=\mathbf{X} \mathbf{w}$ and $\mathbf{u}=\mathbf{Y q}$ to be obtained. It can be done making t' $\mathbf{u}$ maximum and solving the optimization problem

$$
\begin{aligned}
& \underset{\boldsymbol{w}, \boldsymbol{q}}{\operatorname{argmax}}\left\{\mathbf{w}^{\prime} \mathbf{X}^{\prime} \mathbf{Y} \mathbf{q}\right\}, \\
& \text { subject to: } \operatorname{COR}\left(t_{i}, t_{j}\right)=0, \forall i \neq j ;
\end{aligned}
$$




$$
\boldsymbol{w}^{\prime} \boldsymbol{w}=1
$$

\subsection{Partial Least Squares Regression}

Concisely, the NIPALS algorithm ${ }^{1}$ performs the following steps (Abdi, 2010):

- $\quad$ Step 1. $\mathbf{w} \propto \mathbf{X}^{\prime} \mathbf{u} \quad(\mathrm{X}$-weights).

- $\quad$ Step 2. $\mathbf{t} \propto \mathbf{X w} \quad$ (X-factor scores).

- $\quad$ Step 3. $\mathbf{q} \propto \mathbf{Y}^{\prime} \mathbf{t} \quad(\mathrm{Y}$-weights).

- $\quad$ Step 4. $\mathbf{u}=\mathbf{Y q}$ (Y-scores).

At the i-th iteration of the algorithm, the PLS method estimates a single column $\mathbf{t}_{i}$ of the matrix $\mathbf{T}$ as a linear combination of the variables $X$ with coefficients $\mathbf{w}$. This vector of weights $\mathbf{w}$ will compose the i-th column of the matrix of weights $\mathbf{W}$. Since in each iteration the matrix $\mathbf{X}$ is deflated, the columns of $\mathbf{W}$ are non-comparable and, hence, $\mathbf{T} \neq \mathbf{X W}$. In contrast, there exists a matrix $\mathbf{R}=\mathbf{W}\left(\mathbf{P}^{\prime} \mathbf{W}\right)^{-1}$ which allows direct computation of $\mathbf{T}$ by doing $\mathbf{T}=\mathbf{X R}$ (Wold et al., 2004).

The estimated PLS regression equation is:

$$
\widehat{\mathbf{Y}}=\mathbf{T} \widehat{\mathbf{B}}, \text { where } \widehat{\mathbf{B}}=\left(\mathbf{T}^{\prime} \mathbf{T}\right)^{-1} \mathbf{T}^{\prime} \mathbf{Y} .
$$

Moreover, $\widehat{\mathbf{Y}}=\mathbf{X R} \widehat{\mathbf{B}}$ and, thus, $\widehat{\mathbf{B}}_{\mathrm{PLS}}=\mathbf{R} \widehat{\mathbf{B}}=\mathbf{R}\left(\mathbf{T}^{\prime} \mathbf{T}\right)^{-1} \mathbf{T}^{\prime} \mathbf{Y}=\mathbf{R} \mathbf{T}^{\prime} \mathbf{Y}=\mathbf{R} \mathbf{Q}^{\prime}$. Notice that $\mathbf{Q}^{\prime}$ is the $\mathbf{Y}-$ weights matrix composed of the $\mathbf{q}$ vectors estimated in Step 3 of the NIPALS algorithm. Lastly, we can write the predictive model as

$$
\widehat{\mathbf{Y}}=\mathbf{X} \widehat{\mathbf{B}}_{\mathrm{PLS}} \text {, where } \widehat{\mathbf{B}}_{\mathrm{PLS}}=\mathbf{R} \mathbf{Q}^{\prime} \text {. }
$$

\subsection{The Biplot}

The term biplot was introduced by Gabriel (1971) and consists of a graphical representation that reveals important characteristics of data structure, e.g., patterns of correlations between variables or similarities between the observations (Greenacre, 2010). To achieve this, it uses the decomposition of a $(n \times m)$ target matrix $\mathbf{D}$ into the product of two matrices, such that $\mathbf{D}=\mathbf{G} \mathbf{H}^{\prime}$. The dimension of the $\mathbf{G}$ matrix is $(n \times k)$, and the size of $\mathbf{H}$ matrix is $(m \times k)$. Therefore, each element $\mathrm{d}_{\mathrm{ij}}$ of the matrix $\mathbf{D}$ can be written as the scalar product of the $i$ - $t$ h row of the left matrix $\mathbf{G}$ and the $j$-th column of the right matrix $\mathbf{H}$ ', as follows:

$$
\mathbf{D}=\mathbf{G H}^{\prime}=\left(\begin{array}{c}
\mathbf{g}_{1}^{\prime} \\
\vdots \\
\mathbf{g}_{\mathrm{n}}^{\prime}
\end{array}\right)\left(\begin{array}{lll}
\mathbf{h}_{1} & \ldots & \mathbf{h}_{\mathrm{m}}
\end{array}\right)=\left(\begin{array}{ccc}
\mathbf{g}_{1}^{\prime} \mathbf{h}_{1} & \cdots & \mathbf{g}_{1}^{\prime} \mathbf{h}_{\mathrm{m}} \\
\vdots & \ddots & \vdots \\
\mathbf{g}_{\mathrm{n}}^{\prime} \mathbf{h}_{1} & \cdots & \mathbf{g}_{\mathrm{n}}^{\prime} \mathbf{h}_{\mathrm{m}}
\end{array}\right) .
$$

The matrices $\mathbf{G}$ and $\mathbf{H}$ that arise from the decomposition of $\mathbf{D}$ create two sets of points. If these points are two-dimensional (i.e., $k=2$ ), then the rows and columns of $\mathbf{D}$ can be represented employing a twodimensional graph, with the $n$ rows of $\mathbf{G}$ represented by points, and the $m$ columns of $\mathbf{H}$ reproduced in the form of vectors connected to the origin. In the graph, projecting $\mathbf{g}_{\mathrm{i}}^{\prime}$ onto the axis determined by $\mathbf{h}_{\mathrm{j}}$ and then multiplying the norm of that projection by the norm of $\mathbf{h}_{\mathrm{j}}$, the result will be equivalent to the geometric definition of the scalar product, which can also be used to represent the element $d_{i j}$ of the target matrix $\mathbf{D}$, that is:

$$
\mathrm{d}_{\mathrm{ij}}=\mathbf{g}_{\mathrm{i}}^{\prime} \mathbf{h}_{\mathrm{j}}=\left\|\mathbf{g}_{\mathrm{i}}\right\|\left\|\mathbf{h}_{\mathrm{j}}\right\| \cos \theta,
$$

where $\theta$ is the angle formed by the vectors $\mathbf{g}_{\mathrm{i}}$ and $\mathbf{h}_{\mathrm{j}}$. Furthermore, each set of coordinates formed by a row of $\mathbf{G}$ (i.e., $\mathbf{g}_{\mathrm{i}}^{\prime}$ ) is represented as a biplot point, and each column of the transpose of $\mathbf{H}$ (i.e., $\mathbf{h}_{\mathbf{j}}$ ) is plotted as a biplot vector.

\subsection{The Exploratory PLS Biplot}

Given a rank $r$ data matrix, the PLS allows another matrix to be obtained with rank $s$ that is an approximation of the former, in which $s<r$. The PLS dataset is composed of two centered matrices $\mathbf{X}$ and $\mathbf{Y}$, wherein the matrix of predictors $\mathbf{X}$ has the dimension $(n \times m)$, and the matrix of responses $\mathbf{Y}$ has the size

\footnotetext{
${ }^{1}$ In this context, the symbol $\propto$ means 'to normalize the result of the operation'.
} 
$(n \times q)$. Representing a target matrix $\mathbf{D}$ as a juxtaposition of $\mathbf{X}$ and $\mathbf{Y}$, then it will be $(n \times(m+q))$ and denoted as $\mathbf{D}=\left[\begin{array}{ll}\mathbf{X} & \mathbf{Y}\end{array}\right]$. Considering that the number of PLS components extracted is lower than the rank of $\mathbf{X}$, i.e., $k<r$, thus the matrix product $\mathbf{T} \mathbf{P}^{\prime}$ provides an approximation of $\mathbf{X}$. Similarly, the matrix product TQ' gives an approximation for $\mathbf{Y}$, instead of UQ' (Oyedele \& Lubbe, 2015). As a consequence, $\widetilde{\mathbf{D}}$ provides an approximation for $\mathbf{D}$ such that

$$
\widetilde{\mathbf{D}}=\left[\begin{array}{ll}
\widetilde{\mathbf{X}} & \widetilde{\mathbf{Y}}
\end{array}\right]=\left[\begin{array}{ll}
\mathbf{T} \mathbf{P}^{\prime} & \mathbf{T} \mathbf{Q}^{\prime}
\end{array}\right]=\mathbf{T}\left[\begin{array}{ll}
\mathbf{P} & \mathbf{Q}
\end{array}\right]^{\prime} .
$$

Extracting just two components, the dimension of $\mathbf{T}$ is $(n \times 2)$ and the size of the block matrix [P $\mathbf{Q}]$ ' is $(2 \times(m+q))$. So, the rows of $\mathbf{T}$ represent the biplot points in the exploratory PLS biplot, expressing the observations of the sample, while the columns of the block matrix [P $\mathbf{Q}$ ]' indicate the biplot vectors and denote the variables, wherein those from column 1 to $m$ refer to the predictors and from column $(m+1)$ to $(m+q)$ are associated with the responses. Considering each set of biplot vectors separately (predictors and responses), the angle formed by two vectors provides an approximation for the sample correlation coefficient related to the associated variables (Grafelman, 2012). Therefore, if $\angle\left(\mathbf{p}_{\mathrm{i}}^{\prime}, \mathbf{p}_{\mathrm{j}}^{\prime}\right) \cong 0^{\circ}$, it means that the associated variables are strongly correlated because the cosine of the angle between the biplot vectors is close to one. On the other hand, when $\angle\left(\mathbf{p}_{\mathrm{i}}^{\prime}, \mathbf{p}_{\mathrm{j}}^{\prime}\right) \cong 180^{\circ}$ and the biplot vectors point to almost opposite directions, then it indicates a negative but substantial correlation. Lastly, a right angle suggests a weak correlation between the related variables. However, the accuracy of this approximation will depend on how much the variables contribute to each of the underlying components estimated (Bassani, Ambrogi, Coradini, \& Biganzoli, 2010), as well as the biplot explained variance (Greenacre, 2012).

\subsection{The Predictive PLS Biplot}

As previously seen in Section 2.2, the $(m \times q)$ matrix $\widehat{\mathbf{B}}_{\mathrm{PLS}}=\mathbf{R} \mathbf{Q}^{\prime}$ contains the PLS coefficient estimates, in which the $\mathbf{R}$ columns are the transformed PLS X-weights, and $\mathbf{Q}$ is the matrix of Y-weights. In the predictive PLS biplot, the rows of the matrix $\mathbf{R}$ denote the biplot points instead of the rows of $\mathbf{T}$. Further, the columns of $\mathbf{Q}^{\prime}$ symbolize the responses through biplot vectors. Each response can also define a calibrated axis, on which one can project the set of points $\left(\mathbf{r}_{\mathrm{i}}^{\prime}\right)$ to get an approximation of the coefficients. Considering a specific response $Y_{j}$ and a fixed predictor $X_{i}$, each element of the matrix $\widehat{\mathbf{B}}_{\mathrm{PLS}}$ is computed as

$$
\widehat{b}_{P L S_{i j}}=\mathbf{r}_{\mathrm{i}}^{\prime} \mathbf{q}_{\mathrm{j}}=\left\|\mathbf{r}_{\mathrm{i}}\right\|\left\|\mathbf{q}_{\mathrm{j}}\right\| \cos \theta_{\mathbf{r}_{\mathrm{i}}, \mathbf{q}_{\mathrm{j}}}
$$

Therefore, there are two ways to evaluate an approximation for these estimates in the biplot visually. The first manner consists of the calibration of biplot axes (Greenacre, 2010; Oyedele \& Lubbe, 2015) and mentally reading the projection of the biplot point on the biplot axis. In the second mode, the area biplot method is applied (Gower et al., 2010; Oyedele \& Lubbe, 2015), in which the approximation of $\hat{b}_{\mathrm{PLS}}$ ij obtained from the area determined by the origin, the rotated biplot point $\mathbf{r}_{\mathrm{i}}^{\prime}$, and the endpoint of $\mathbf{q}_{\mathrm{j}}$. The area and position of the triangles furnish other relevant information about the PLS regression coefficients, such as the signal and the importance of each predictor to the model.

\section{Application}

Teams of individuals working together to achieve a common goal are a central part of daily life in modern organizations (Mathieu, Tannenbaum, Donsbach, \& Alliger, 2014). By bringing together individuals with different skills and knowledge, teams emerge as a competitive asset in the ever-changing organizational environment. When teams are created, the ultimate goal is to generate value for the organization. Accordingly, studying team effectiveness and the conditions that enable the team to be effective has been a central concern for both research and practice (Kozlowski \& Ilgen, 2006).

\subsection{Variables}

In the present research, in line with previous studies (e.g., Hackman, 1987), we consider team effectiveness as a multidimensional construct. Thus, in this study, team effectiveness is evaluated through two criteria: team performance and the quality of group experience. Team performance $\left(\mathrm{Y}_{1}\right)$ refers to the extent to which team outcomes respect the standards set by the organization, in terms of quantity, quality, delivery time and 
costs (Rousseau \& Aubé, 2010). The quality of the group experience $\left(\mathrm{Y}_{2}\right)$ is related to the quality of the social climate within the team (Aubé \& Rousseau, 2005).

Team effectiveness will be considered, in the present study, as the result of the role played by thirteen variables: team trust ( 2 dimensions), team psychological capital (4 dimensions), collective behavior, transformational leadership, intragroup conflict (2 dimensions), team psychological safety, and team cohesion (2 dimensions). Each variable will be briefly described as follows.

Team trust refers to the aggregate levels of trust that team members have in their fellow teammates (Langfred, 2004) and has been conceptualized as a bidimensional construct: the affective dimension of team trust $\left(\mathrm{X}_{1}\right)$ is related to the perception of the presence of shared ideas, feelings, and concerns within the team; the task dimension of team trust $\left(\mathrm{X}_{2}\right)$ has been associated with the recognition by team members of the levels of professionalism and competence of their teammates and on their ability to appropriately perform the tasks (McAllister, 1995).

Team psychological capital (PsyCap) can be defined as a team positive psychological state characterized by: having confidence (efficacy) to succeed in challenging tasks; making a positive attribution (optimism) about succeeding now and in the future; persevering, and when necessary, redirecting paths to goals (hope) in order to be effective; and having the ability to bounce back from challenges and setbacks (resilience) (Luthans, Avolio, Avey, \& Norman., 2007; Luthans \& Youssef-Morgan, 2017; Walumbwa Luthans, Avey, \& Oke, 2011). In summary, team PsyCap includes four team psychological resources: team efficacy $\left(\mathrm{X}_{3}\right)$, team optimism $\left(\mathrm{X}_{4}\right)$, team hope $\left(\mathrm{X}_{5}\right)$, and team resilience $\left(\mathrm{X}_{6}\right)$.

Collective behavior $\left(\mathrm{X}_{7}\right)$ refers to the members' tendency to coordinate, evaluate, and utilize task inputs from other team members when performing a group task (Driskell, Salas, \& Hughes, 2010).

Transformational leadership $\left(\mathrm{X}_{8}\right)$ can be defined as a leadership style that encourages followers to do more than they originally expected, broadening and changing their interests and leading to conscientiousness and acceptance of the team's purposes (Bass, 1990). Carless, Wearing and Mann (2000) described transformational leaders as those who exhibit the following seven behaviors: they 1) communicate a vision; 2) develop staff; 3) provide support for them to work towards their objectives through coordinated team work; 4) empower staff; 5) are innovative by using non-conventional strategies to achieve their goals; 6) lead by example; 7) are charismatic.

Intragroup conflict can be defined as a disagreement that is perceived as creating tension at least by one of the parties involved in an interaction (De Dreu \& Weingart, 2003). Conflicts in teams may emerge as a result of the presence of different ideas about the tasks performed $\left(\mathrm{X}_{9}\right)$ - task conflict - or may be related to differences between team members in terms of values or personalities $\left(\mathrm{X}_{10}\right)$ - affective conflict (Jehn, 1994).

Team psychological safety $\left(\mathrm{X}_{11}\right)$ relates to team members' perceptions about what the consequences will be of taking interpersonal risks at the work environment. It means taking beliefs for granted about how others will react when one speaks up or participates. It is a confidence climate that comes from mutual respect and trust between members (Edmondson, 1999).

Team cohesion can be defined as the team members' inclination to create social bonds, resulting in the group sticking together, remaining united, and wanting to work together (Carron 1982; Salas, Grossman, Hughes, \& Coultas, 2015). It can be related to the task or the affective system of the team. Task cohesion $\left(\mathrm{X}_{12}\right)$ refers to the shared commitment among members towards achieving a goal that requires the collective efforts of the group. Social cohesion $\left(\mathrm{X}_{13}\right)$ refers to shared liking or attraction to the group and to the nature and quality of the emotional bonds of friendship, liking, caring, and closeness among group members (Chang \& Bordia, 2001).

\subsection{Sample and Data Collection Procedure}

Organizations were selected by convenience, using the personal and professional contacts network of the research team. To collect data, key stakeholders in each organization (CEOs or human resources managers) were contacted to explain the purpose and requirements of the study. When the organization agreed to participate, the selection of teams for the survey was based on the following criteria (Cohen \& Bailey, 1997): teams must be composed of at least three members; should be perceived by themselves and others as a team; they have to regularly interact, interdependently, to accomplish a common goal; and they must have a formal supervisor who is responsible for the actions of the team.

Data was collected following two strategies. In most organizations, questionnaires were filled in during team meetings, in the presence of a member of the research team. When it was not possible to implement this strategy, they were filled in online via an electronic platform. Data was obtained from 104 teams and their respective leaders. After eliminating from the sample teams with a team members' response rate below $50 \%$ and participants with more than $10 \%$ of missing values, the remaining sample had a total of 82 teams. In this remaining sample, missing values in the questionnaires were replaced by the item average (in case 
of a random distribution) or by expectation-maximization (EM) method (in case of a non-random distribution).

The 82 teams of the sample are from 57 Portuguese companies. Forty-two per cent of these organizations are small, and the most representative sector is the services sector (73\%). Team size ranged from 3 to 18 members, with an average of approximately 6 members $(\mathrm{SD}=3.55)$. Of the team members $(\mathrm{N}=353), 67 \%$ were female, $63.3 \%$ had secondary education or less, with the remaining $36.7 \%$ having a higher education background. The mean age was approximately 38 years old $(\mathrm{SD}=12.33)$. The average team tenure was approximately 6 years $(\mathrm{SD}=7.25)$. Regarding team leaders $(\mathrm{N}=82), 57 \%$ were male, the mean age was about 42 years old $(\mathrm{SD}=10.86)$ and $55.7 \%$ had a higher education background. Leaders had, on average, 5 years of experience as leader of the current team $(\mathrm{SD}=4.87)$.

\subsection{Measures}

Apart from team performance that was assessed by team leaders, all variables were measured by team members. The measures used are identified as follows: team performance was measured with a scale developed by Rousseau and Aubé (2010), which has five items; quality of the group experience was assessed with the scale developed by Aubé and Rousseau (2005), which is composed of three items; team trust was evaluated with the scale developed by McAllister (1995), which is constituted by 10 items; team psyCap was measured with the scale developed by Luthans et al. (2007), which is composed of 24 items; collective behavior was measured with the scale developed by Driskell et al. (2010), which has 10 items; transformational leadership was measured with the scale developed by Carless et al. (2000), which is composed of seven items; intragroup conflict was evaluated with the scale developed by Dimas and Lourenço (2015), which is composed of nine items; team psychological safety was assessed with the scale developed by Edmonson (1999), which is composed of seven items; team cohesion was measured with the scale developed by Chang and Bordia (2001). Team trust and team psycap were assessed using 6-point scales, intragroup conflict and team psychological safety were evaluated on 7-point scales and the remaining variables were measured on 5-point scales.

\subsection{PLS Biplot Results}

In order to reveal a linear relation between the variables describing team effectiveness and the explanatory variables, the PLS was used to construct the external and internal models. First, the predictor matrix $\mathbf{X}_{82 \times 13}$ and the response matrix $\mathbf{Y}_{82 \times 4}$ were centered and scaled. Next, the NIPALS algorithm was used to decompose the data matrices and to extract two PLS components, yielding the matrices $\mathbf{T}_{82 \times 2}=\left[\mathrm{T}_{1} \mathrm{~T}_{2}\right]$, $\mathbf{P}_{13 \times 2}, \mathbf{U}_{82 \times 2}, \mathbf{Q}_{4 \times 2}, \mathbf{W}_{13 \times 2}, \mathbf{R}_{13 \times 2}$, and $\mathbf{B}_{13 \times 2}$. The latter contains the estimates of the PLS regression coefficients, according to Table 1 .

Table 1. Punctual estimates of the PLS regression coefficients.

\begin{tabular}{lccc}
\hline Predictor name & $\begin{array}{c}\text { Predictor } \\
\text { identification }\end{array}$ & $\begin{array}{c}\widehat{\boldsymbol{\beta}}_{\mathbf{1}} \text { related to Team } \\
\text { performance }\left(\boldsymbol{Y}_{\mathbf{1}}\right)\end{array}$ & $\begin{array}{c}\widehat{\boldsymbol{\beta}}_{2} \text { related to Quality } \\
\text { of the group experience } \\
\left(\boldsymbol{Y}_{\mathbf{2}}\right)\end{array}$ \\
\hline Team trust (affective) & $\mathrm{X}_{1}$ & 0.076 & 0.079 \\
Team trust (task) & $\mathrm{X}_{2}$ & 0.005 & 0.141 \\
Team efficacy & $\mathrm{X}_{3}$ & 0.105 & 0.033 \\
Team optimism & $\mathrm{X}_{4}$ & 0.144 & -0.027 \\
Team hope & $\mathrm{X}_{5}$ & 0.076 & 0.068 \\
Team resilience & $\mathrm{X}_{6}$ & 0.023 & 0.075 \\
Collective behavior & $\mathrm{X}_{7}$ & 0.047 & 0.095 \\
Transformational leadership & $\mathrm{X}_{8}$ & 0.055 & 0.043 \\
Task conflict & $\mathrm{X}_{9}$ & 0.017 & -0.124 \\
Affective conflict & $\mathrm{X}_{10}$ & 0.051 & -0.154 \\
Team psychological safety & $\mathrm{X}_{11}$ & 0.090 & 0.053 \\
Task cohesion & $\mathrm{X}_{12}$ & 0.059 & 0.103 \\
Social cohesion & $\mathrm{X}_{13}$ & -0.035 & 0.109 \\
\hline
\end{tabular}

The first PLS component $\mathrm{T}_{1}$ explains $56.5 \%$ of the data variability, while the proportion of variance explained by $\mathrm{T}_{2}$ is $9.5 \%$. Fig. 1 shows the exploratory PLS biplot, in which the (black) biplot points (Xscores $\mathbf{t}_{\mathrm{i}}^{\prime}$ ) represent the 82 teams, the blue biplot vectors depict the responses (Y-loadings $\mathbf{q}_{\mathrm{i}}^{\prime}$ ), and the red biplot vectors symbolize the predictors (X-loadings $\left.\mathbf{p}_{\mathrm{i}}^{\prime}\right)$. 
Fig. 1 provides an approximation of the correlation structures of the data, but it must be taken into account that the total proportion of variance explained by the two components $\mathrm{T}_{1}$ and $\mathrm{T}_{2}$ is $66 \%$. Table 2 shows some significantly correlated variables evidenced by the biplot $\left(\mathrm{X}_{2}\right.$ and $\mathrm{X}_{12}, \mathrm{X}_{7}$ and $\mathrm{X}_{12}, \mathrm{X}_{3}$ and $\mathrm{X}_{11}$, and $\mathrm{X}_{9}$ and $\mathrm{X}_{10}$ ), a pair of variables that displayed negative correlation $\left(\mathrm{X}_{2}\right.$ and $\left.\mathrm{X}_{9}\right)$, and others that manifested a weak correlation visually $\left(\mathrm{X}_{5}\right.$ and $\mathrm{X}_{13}, \mathrm{X}_{6}$ and $\left.\mathrm{X}_{13}\right)$, all of them flanked by the exact sample correlation coefficients. Table 2 is not exhaustive, and it is possible to pinpoint other exciting examples regarding the correlation structure in Fig. 1, e.g., the weak correlation between the two responses (the correct sample correlation is $\cong 0.28$ ). Moreover, all of the variables are positively associated with the first PLS component $\mathrm{T}_{1}$, except Task conflict $\left(\mathrm{X}_{9}\right)$ and Affective conflict $\left(\mathrm{X}_{10}\right)$, which are negatively associated. Regarding $\mathrm{T}_{2}$, the predictor Team trust-affective $\left(\mathrm{X}_{1}\right)$ is negligibly correlated, and the predictors Team trusttask $\left(\mathrm{X}_{2}\right)$, Collective behavior $\left(\mathrm{X}_{7}\right)$, Task cohesion $\left(\mathrm{X}_{12}\right)$, and Social cohesion $\left(\mathrm{X}_{13}\right)$ are negatively correlated.

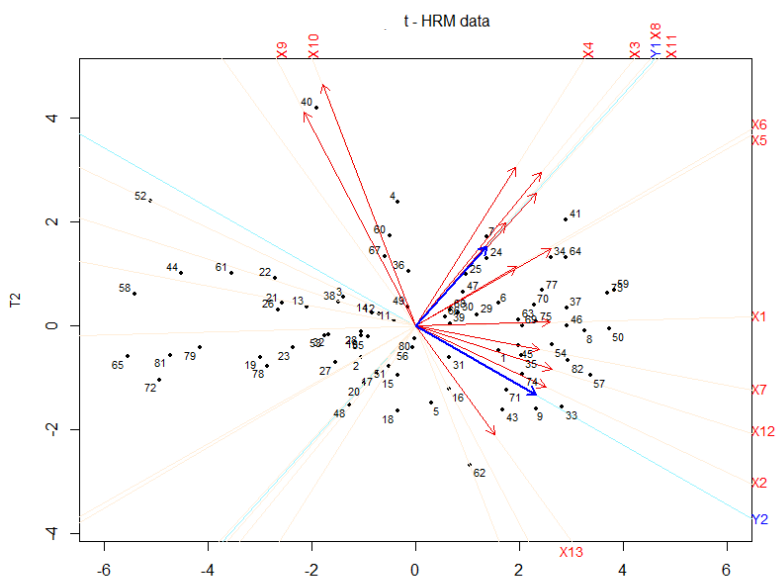

Fig. 1. Exploratory PLS biplot - sample and variables representation.

Table 2. Correlation approximation by biplot vectors and sample correlation coefficients.

\begin{tabular}{lc}
\hline \multicolumn{1}{c}{ Variables } & Correct Correlation Coefficient $(\boldsymbol{r})$ \\
\hline $\mathrm{X}_{2}$ (Team trust - task) and $\mathrm{X}_{12}$ (Task cohesion) & 0.71 \\
$\mathrm{X}_{7}$ (Team efficacy) and $\mathrm{X}_{12}$ (Task cohesion) & 0.70 \\
$\mathrm{X}_{3}$ (Team efficacy) and $\mathrm{X}_{11}$ (Team psychological safety) & 0.73 \\
$\mathrm{X}_{9}$ (Task conflict) and $\mathrm{X}_{10}$ (Affective conflict) & 0.85 \\
$\mathrm{X}_{2}$ (Team trust - task) and $\mathrm{X}_{9}$ (Task conflict) & -0.60 \\
$\mathrm{X}_{5}$ (Team hope) and $\mathrm{X}_{13}$ (Social cohesion) & 0.35 \\
$\mathrm{X}_{6}$ (Team resilience) and $\mathrm{X}_{13}$ (Social cohesion) & 0.25 \\
\hline
\end{tabular}

For comparison purposes only, Fig. 2 shows the results of the area biplot method. With respect to response Team performance $\left(\mathrm{Y}_{1}\right)$ - left biplot, the predictors Team efficacy $\left(\mathrm{X}_{3}\right)$, Team optimism $\left(\mathrm{X}_{4}\right)$, and Team psychological safety $\left(\mathrm{X}_{11}\right)$ stand out as the most influential variables to the model, since the triangle related to the regression coefficients $b_{3}, b_{4}$, and $b_{11}$ show the most significant area. On the other side, the variables with the least positive impact on the model are Team trust-task $\left(\mathrm{X}_{2}\right)$ and Team task conflict $\left(\mathrm{X}_{9}\right)$, because they are related to the smallest areas. Further, the predictor Social cohesion $\left(\mathrm{X}_{13}\right)$ affects Team performance negatively, given that the triangle position is on the right side of the biplot axis. In its turn, regarding the response Quality of the group experience $\left(\mathrm{Y}_{2}\right)$, the most important predictors are Task conflict $\left(\mathrm{X}_{9}\right)$, Affective conflict $\left(\mathrm{X}_{10}\right)$, Team trust-task $\left(\mathrm{X}_{2}\right)$, Task cohesion $\left(\mathrm{X}_{12}\right)$, and Social cohesion $\left(\mathrm{X}_{13}\right)$, with the first two in a negative way. All these findings are following the PLS results shown in Table 2, but one can easily reach the same conclusions through Fig. 1 (exploratory PLS biplot). 

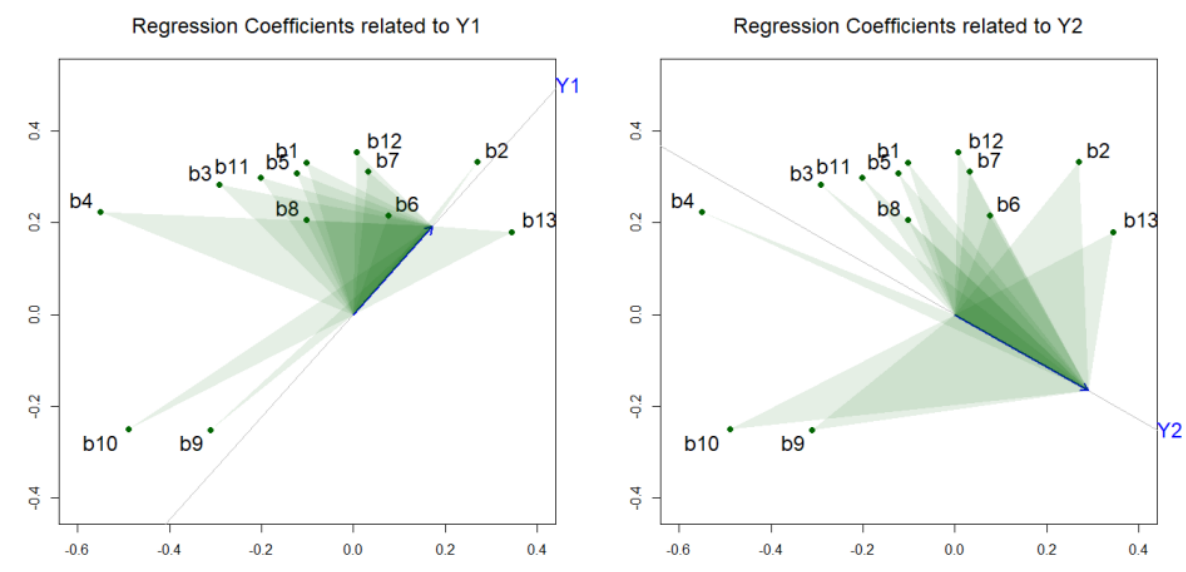

Fig. 2. Area biplot Method applied to the team effectiveness dataset.

Fig. 3 brings a modified version of the exploratory PLS biplot, in which all of the biplot vectors are projected onto the calibrated biplot axis $Y_{1}$. One more time, the most significant vector projections refer to Team efficacy $\left(\mathrm{X}_{3}\right)$, Team optimism $\left(\mathrm{X}_{4}\right)$, and Team psychological safety $\left(\mathrm{X}_{11}\right)$, as well as the less significant projection referring to Team trust-task $\left(\mathrm{X}_{2}\right)$. Beyond that, only the projection related to the variable Social cohesion $\left(\mathrm{X}_{13}\right)$ falls on the negative part of the biplot axis. The approximation of the regression coefficients related to the dependent variable Quality of the group experience is represented in Fig. 4, where the biplot vectors are projected onto the biplot axis $\mathrm{Y}_{2}$. In this case, similarly to the results of the area biplot method, the largest projections indicate the more relevant variables. On the negative side, the predictors Task conflict $\left(\mathrm{X}_{9}\right)$ and Affective conflict $\left(\mathrm{X}_{10}\right)$ are the most influential in the model, while the explanatory variables Team trust-task $\left(\mathrm{X}_{2}\right)$, Task cohesion $\left(\mathrm{X}_{12}\right)$, and Social cohesion $\left(\mathrm{X}_{13}\right)$ have the most significant and positive impact concerning $\mathrm{Y}_{2}$.

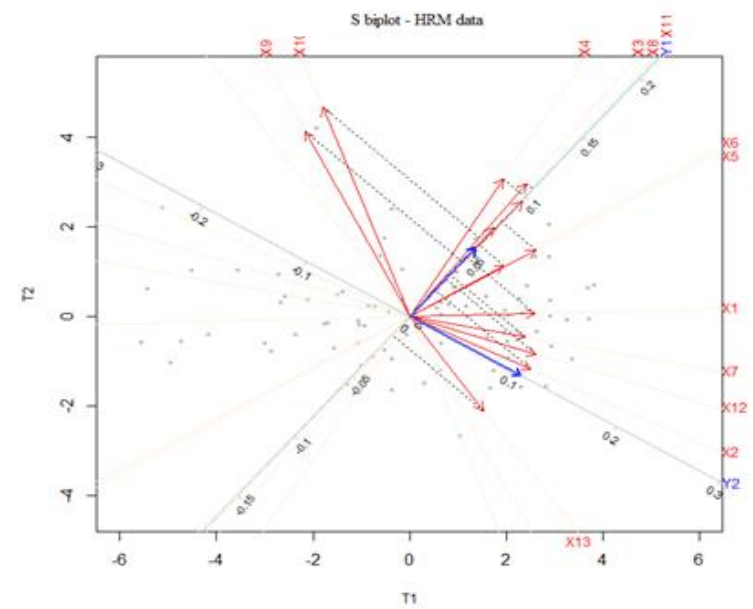

Fig. 3. Visual approximation of the regression coefficients (response $Y_{1}$ ). 


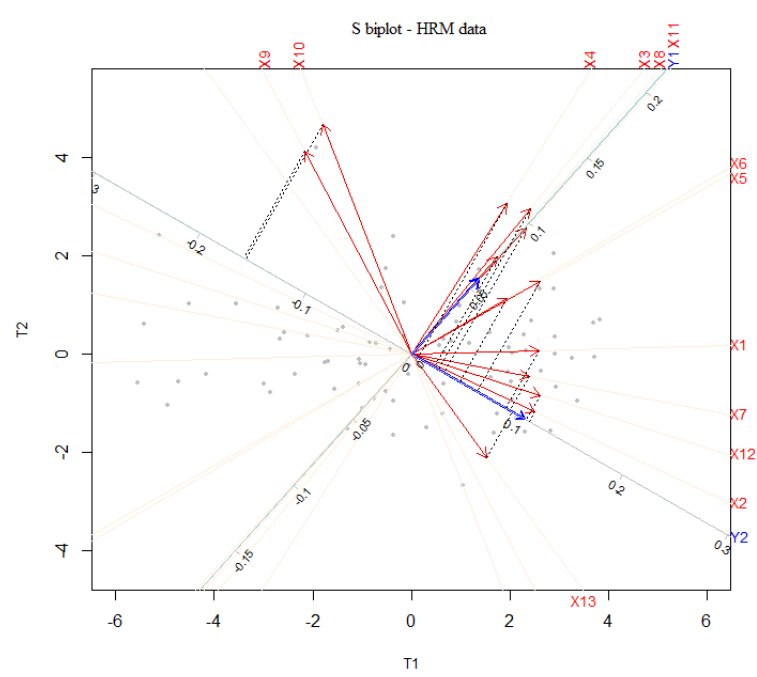

Fig. 4. Visual approximation of the regression coefficients (response $Y_{2}$ ).

\section{Discussion and Conclusions}

Regarding the application of the method we use in this work, the results point to the "validity" of such an application concerning the relationships found between the group processes and the team output variables considered. In fact, overall, the most significant results found in our study suggest relationships between the predictors and the criteria that are convergent with the literature.

One of the results points out the relevant role of cohesion as a predictor of team outcomes but the different behavior of each one of the team cohesion dimensions. Indeed, task cohesion $\left(\mathrm{X}_{12}\right)$ showed a positive relationship with both team effectiveness criteria (although with higher magnitude regarding the quality of the group experience); however, social cohesion $\left(\mathrm{X}_{13}\right)$, although it emerged as one of the most relevant positive predictors of the quality of group experience, revealed a negative influence on team performance. These results are in line with the literature. Firstly, team cohesion is recognized by researchers as one of the most influential factors on group behavior and, consequently on group outcomes (Carron \& Brawley, 2000; Dionne, Yammarino, \& Spangler, 2004). Secondly, and despite that, the literature, namely a meta-analysis conducted by Mullen and Cooper (1994), also suggests that the link between social cohesion and task cohesion with team outcomes can be different. Task cohesion tends to be positively associated with team outcomes, but social cohesion can have a more complex relationship with team outcomes due the fact that social cohesion, although it increases the willingness to help each other and to cooperate, can also lead to uncritical acceptance of solutions and to groupthink (Janis, 1972). Thus, social cohesion can both increase the sense of belonging to a group, contributing to a positive perception of the group experience (quality of group experience), and decrease team performance, as suggested by our study.

Another interesting result to highlight is related to the negative relationship of both conflict types - task conflict $\left(\mathrm{X}_{9}\right)$ and affective conflict $\left(\mathrm{X}_{10}\right)$ - with the quality of group experience and the less clear role of task conflict in team performance. Indeed, task conflict revealed a negative relation with the quality of the group experience and a positive (albeit low-level) relation with team performance. These results tend to converge with the literature. On the one hand, the literature points out that conflict is always experienced as a negative experience (e.g., Jehn, Greer, Levine, \& Szulanski, 2008) and, as a result tends to have a negative influence on the attitudes of team members towards the group. However, on the other hand, studies are not totally consensual with respect to its effects on team performance, especially in what concerns to task conflict (De Wit, Greer, \& Jehn, 2012; Dimas \& Lourenço, 2015). In fact, most studies found either negative associations between task conflict and team performance (e.g., Janssen, Van de Vliert, \& Veenstra, 1999) or a nonsignificant relation (e.g., Jordan \& Troth, 2004), and a meta-analysis conducted by De Dreu and Weingart (2003) supported those findings. However, more recently De Wit et al. (2012) conducted a new meta-analysis and concluded that the effects of task conflict on team outcomes are less negative (or even positive) as compared to affective conflict. Overall, the studies tend to suggest that, in certain circumstances, task conflict may be positively related to group outcomes (e.g., De Wit et al., 2012) emphasizing the role of moderators, such as the conflict-handling strategies used in the team.

It is also interesting to mention the positive role of team trust $\left(\mathrm{X}_{1}\right.$ and $\left.\mathrm{X}_{2}\right)$ in team results and the more significant role of team task trust $\left(\mathrm{X}_{2}\right)$ compared to team social trust $\left(\mathrm{X}_{1}\right)$. Again, our results are supported 
by the literature which indicates that trust represents an important determinant of team effectiveness. In this regard, Dirks and Ferrin (2001) pointed out in their meta-analysis that team trust is positively related to performance and team satisfaction (an indicator of the quality of group experience). The fact that, in the present study, task trust has showed to be a more important predictor of performance than social trust can be explained by the fact that our sample is composed of work teams in productive organizations, where trust in the members' skills and their professionalism for the accomplishment of the tasks is more critical.

Finally, it is important to mention the role of team psychological safety $\left(\mathrm{X}_{11}\right)$, team self-efficacy $\left(\mathrm{X}_{3}\right)$ and team optimism $\left(\mathrm{X}_{4}\right)$ as positive predictors of team performance. Like the variables that we addressed above, the results obtained are supported by the literature. Regarding the relationship between team psychological safety and team performance, previous studies suggest that team performance can be facilitated, directly or indirectly, by the presence of a psychological security climate (e.g., Edmondson, 1999). According to these studies, team performance is increased by a group climate in which team members are encouraged to express themselves without fear of the evaluations of the rest of the group. Regarding team efficacy and team optimism (dimensions of PsyCap), several studies show that collective PsyCap is positively related to team performance (e.g., Norman, Avey, Nimnicht, \& Pigeon, 2010; Wallumbwa et al., 2011). Additionally, previous research suggests that when team members have a collective belief in their ability to be effective, they explore and share knowledge and are more prepared to implement new ways of achieving results, because they believe these behaviors will lead to higher levels of performance (Bandura, 1977). Similarly, a team with optimistic beliefs has positive expectations, is usually more actively involved in tasks than a team with a low level of optimism and use more adaptive coping skills when obstacles occur (Avey, Reichard, Luthans, \& Mhatre, 2011).

In general, the interpretation method proposed in this work provided excellent results in the application performed in Section 3, since it was able to capture the most critical variables for the model, correctly assigned the signals of the regression coefficients and gave an approximation to their values directly in the exploratory PLS biplot. Nevertheless, some inconsistencies were detected. For example, regarding the response $Y_{1}$, one can see in Table 2 that $\hat{\beta}_{41}>\hat{\beta}_{31}$, but the projections of the biplot vectors corresponding to $\mathrm{X}_{4}$ and $\mathrm{X}_{3}$ over the biplot axis yield the opposite result (Fig. 3). In the same sense, the projections of the vectors related to $X_{6}$ and $X_{9}$ seem to be overestimated considering the associated values $\left(\hat{\beta}_{61}\right.$ and $\left.\hat{\beta}_{91}\right)$ in Table 2. Although with less intensity, the same occurs in Fig. 4, where the projections are made over the biplot axis $\mathrm{Y}_{2}$.

However, we should keep in mind that biplot is a visualization method whose purpose is to provide a general idea of latent structures in the data, not to mention that the interpretation technique suggested in this paper provides only an approximation of the coefficients, which will be closer to the real values of the estimates, the higher the PLS components' ability to explain the variance.

Acknowledgments. This work was partially supported by The Center for Research and Development in Mathematics and Applications (CIDMA) and by The Center for Business and Economics Research (CeBER) through the Portuguese Foundation for Science and Technology (FCT - Fundação para a Ciência e a Tecnologia), references UIDB/04106/2020, UIDP/04106/2020 and UIDB/05037/2020.

\section{References}

Abdi, H.: Partial least squares regression and projection on latent structure regression (PLS regression). WIREs Comput. Stat. 2, 97-106 (2010).

Avey, J.B., Reichard, R.J., Luthans, F., Mhatre, K.H. Meta-analysis of the impact of positive psychological capital on employee attitudes, behaviors, and performance. Human resource development quarterly 22(2), 127-152 (2011).

Aubé, C., Rousseau, V.: Team goal commitment and team effectiveness: the role of task interdependence and supportive behaviors. Group Dynamics Theory Research and Practice 9, 189-204 (2005).

Bandura, A.: Self-efficacy: Toward a unifying theory of behavioral change. Psychological Review 84(2), 191-215 (1977)

Bass, B.M.: From transactional to transformational leadership: Learning to share the vision. Organizational Dynamics 18(3), 19-31 (1990).

Bassani, N., Ambrogi, F., Coradini, D., Biganzoli, E. Use of Biplots and Partial Least Squares Regression in Microarray Data Analysis for Assessing Association between Genes Involved in Different Biological Pathways. Computational Intelligence Methods for Bioinformatics and Biostatistics. In: 7th International Meeting, pp. 123 -134. Springer, Palermo (2010).

Belsley, D. A., Kuh, E., and Welsch, R. E.: Regression Diagnostics - Identifying Influential Data and Sources of Collinearity. Wiley-Interscience, New Jersey (2004). 
Carless, S., Wearing, L., Mann, L. A.: Short measure of transformational leadership. Journal of Business and Psychology 14(3), 389-405 (2000).

Carron, A.V.: Cohesiveness in Sport Groups: Interpretations and Considerations. Journal of Sport Psychology, 4, 123-138 (1982).

Carron, A.V., Brawley, L.R.: Cohesion: Conceptual and measurement issues. Small Group Research 31, 89-106 (2000).

Chang, A., Bordia, P.: A Multidimensional Approach to the Group Cohesion Group Performance Relationship. Small Group Research, 32(4), 379-405 (2001).

Cohen, S.G., Bailey, D.E.: What makes teams work: Group effectiveness research from the shop floor to the executive suite. Journal of Management 23(3), 239-290 (1997).

De Dreu, C.K.W., Weingart, L.R.: Task versus relationship conflict, team performance, and team member satisfaction: A meta-analysis. Journal of Applied Psychology 88(4), 741-749 (2003).

De Wit, F.R., Greer, L.L., Jehn, K.A.: The paradox of intragroup conflict: a meta-analysis. Journal of Applied Psychology 97(2), 360-390 (2012).

Dimas, I.D., Lourenço, P.R.: Intragroup conflict and conflict management approaches as determinants of team performance and satisfaction: Two field studies. Negotiation and conflict management research $8(3)$, 174-193 (2015).

Dionne, S.D., Yammarino, F.J., Atwater, L.E., Spangler, W.D.: Transformational leadership and team performance. Journal of Organizational Change Management 17(2), 177-193 (2004).

Dirks, K.T., Ferrin, D.L.: The role of trust in organizational settings. Organization Science 12(4), 450-467 (2001).

Driskell, J.E., Salas, E., Hughes, S.: Collective orientation and team performance: Development of an individual differences measure. Human Factors 52(2), 316-328 (2010).

Edmondson, A.: Psychological Safety and Learning Behavior in Work Teams. Administrative Science Quarterly 44(2), 350-383 (1999).

Gabriel, K.R.: The biplot graphic display of matrices with application to principal component analysis. Biometrika 58, 453-467 (1971).

Geladi, P.; Kowalsky, B.R.: Partial Least Squares Regression: A Tutorial. Analytica Chimica Acta, 186, 117 (1986)

Gower, J.C., Groenen, P.J.F., Van de Velden, M.: Area biplots. Journal of Computational and Graphical Statistics 19, 46-61 (2010).

Graffelman, J. Linear-Angle Correlation Plots: New Graphs for Revealing Correlation Structure. Journal of Computational and Graphical Statistics 22(1), 92-106 (2012).

Greenacre, M.: Biplots in Practice. FBBVA, (2010).

Greenacre, M.: Contribution Biplots. Journal of Computational and Graphical Statistics 22(1), 107-122 (2012).

Hackman, J. R.: The design of work teams. In J. Lorsch (Ed.), Handbook of organizational behavior, pp. 315-342. Prentice-Hall, Englewood Cliffs, NJ (1987).

Janis, I.L.: Victims of groupthink: A psychological study of foreign-policy decisions and fiascoes. Houghton Mifflin (1972).

Janssen, O., Van de Vliert, E., Veenstra, C.: How task and person conflict shape the role of positive interdependence in management teams. Journal of Management 25(2), 117-141 (1999).

Jehn, K.A.: Enhancing effectiveness: An investigation of advantages and disadvantages of value-based intragroup conflict. International Journal of Conflict Management 5, 223-238 (1994).

Jehn, K.A., Greer, L., Levine, S., Szulanski, G.: The effects of conflict types, dimensions, and emergent states on group outcomes. Group Decision and Negotiation 17(6), 465-495 (2008).

Jordan, P.J., Troth, A.C.: Managing emotions during team problem solving: Emotional intelligence and conflict resolution. Human Performance 17(2) 195-218. (2004).

Kozlowski, S.W., Ilgen, D.R.: Enhancing the effectiveness of work groups and teams. Psychological science in the public interest 7(3), 77-124 (2006).

Koch, I.: Analysis of multivariate and high-dimensional data. Cambridge University Press, New York (2014).

Langfred, C.W.: Too much of a good thing? Negative effects of high trust and individual autonomy in selfmanaging teams. Academy of Management Journal, 47(3), 385-399 (2004).

Luthans, F., Avolio, B.J., Avey, J.B., Norman, S.M.: Positive psychological capital: Measurement and relationship with performance and satisfaction. Personnel Psychology 60(3), 541-572. (2007).

Luthans, F., Youssef-Morgan, C.M.: Psychological Capital: An Evidence-Based Positive Approach. Annual Review of Organizational Psychology and Organizational Behavior 4(1), 339-366 (2017). 
Mathieu, J.E., Gallagher, P.T., Domingo, M.A., Klock, E.A.: Embracing complexity: Reviewing the past decade of team effectiveness research. Annual Review of Organizational Psychology and Organizational Behavior 6, 17-46 (2019).

Mathieu, J.E., Tannenbaum, S.I., Donsbach, J.S., Alliger, G.M.: A review and integration of team composition models: Moving toward a dynamic and temporal framework. Journal of Management 40(1), 130-160 (2014).

McAllister, D.: Affect and cognition-based trust as foundations for interpersonal cooperation in organizations. Academy of Management Journal 38(1), 24-59 (1995).

Mullen, B., Cooper, C.: The relation between group cohesiveness and performance: An integration. Psychological Bulletin 115, 210-227 (1994).

Norman, S.M., Avey, J.B., Nimnicht, J.L., Pigeon, N.: The interactive effects of psychological capital and organizational identity on employee organizational citizenship and deviance behaviors. Journal of Leadership \& Organizational Studies 17(4), 380-391 (2010).

Oyedele, O.F., Lubbe S.: The construction of a partial least squares biplot. Journal of Applied Statistics 42(11), 2449-2460 (2015).

Ringle, C.M., Sarstedt, M., Mitchell, R., Gudergan, S.P.: Partial least squares structural equation modeling in human resource management research. The International Journal of Human Resource Management (2018).

Rousseau, V., Aubé, C.: Team self-managing behaviors and team effectiveness: The moderating effect of task routineness. Group \& Organization Management 35(6), 751-781 (2010),

Salas, E., Grossman, R., Hughes, A.M, Coultas, C.W.: Measuring Team Cohesion: Observations from the Science. Human Factors 57(3), 365-374 (2015).

Walumbwa, F.O., Luthans, F., Avey, J.B., Oke, A.: Authentically leading groups: The mediating role of collective psychological capital and trust. Journal of Organizational Behavior 32(1), 4-24. (2011).

Wold, S., L. Eriksson, J. Trygg, N. Kettaneh. The PLS method - partial least squares projections to latent structures - and its applications in industrial RDP (research, development, and production). Umea University, Umea ( 